Article

\title{
Simplified Normalization of C-Band Synthetic Aperture Radar Data for Terrestrial Applications in High Latitude Environments
}

\author{
Barbara Widhalm ${ }^{1, *}$, Annett Bartsch ${ }^{1,2}$ and Robert Goler ${ }^{1}$ \\ 1 ZAMG-Zentralanstalt für Meteorologie und Geodynamik, Hohe Warte 38, 1190 Vienna, Austria; \\ annett.bartsch@zamg.ac.at (A.B.); robert.goler@zamg.ac.at (R.G.) \\ 2 b.geos, Industriestrasse 1, 2100 Korneuburg, Austria \\ * Correspondence: barbara.widhalm@zamg.ac.at; Tel.: +43-1-36026-2234
}

Received: 31 January 2018; Accepted: 3 April 2018; Published: 4 April 2018

\begin{abstract}
Synthetic aperture radar (SAR) applications often require normalization to a common incidence angle. Angular signatures of radar backscatter depend on surface roughness and vegetation cover, and thus differ, from location to location. Comprehensive reference datasets are therefore required in heterogeneous landscapes. Multiple acquisitions from overlapping orbits with sufficient incidence angle range are processed in order to obtain parameters of the location specific normalization function. We propose a simpler method for C-band data, using single scenes only. It requires stable dielectric properties (no variations of liquid water content). This method is therefore applicable for frozen conditions. Winter C-band data have been shown of high value for a number of applications in high latitudes before. In this paper we explore the relationship of incidence angle and Sentinel-1 backscatter across the tundra to boreal transition zone. A linear relationship (coefficient of determination $\mathrm{R}^{2}=0.64$ ) can be found between backscatter and incidence angle dependence (slope of normalization function) as determined by multiple acquisitions on a pixel by pixel basis for typical land cover classes in these regions. This allows a simplified normalization and thus reduced processing effort for applications over larger areas.
\end{abstract}

Keywords: synthetic aperture radar; normalization; tundra; frozen soil

\section{Introduction}

Radar backscatter intensity depends on sensor parameters like incidence angle, polarisation and wavelength, as well as on target parameters such as surface roughness, vegetation structure and dielectric properties [1]. The incidence angle has a major effect on backscatter values of Synthetic Aperture Radar (SAR) acquisitions. It is therefore necessary to eliminate this effect and to normalize the scenes to a single incidence angle in order to achieve comparability of images with different acquisition geometry for many applications. Various approaches for angular normalization exist. Advanced approaches are based on histogram or frequency matching [2], while many empirical approaches rely on fitting a first or second order polynomial to incidence angle and backscatter values [3-8]. Previous studies $[7,9]$ have pointed out that the relationship between incidence angle and backscatter can be considered as linear for a limited incidence angle range. Mäkynen et al. [9] found that the incidence angle range from $19^{\circ}$ to $46^{\circ}$, which approximately corresponds to the incidence angle range covered by Sentinel-1, is usually well described by a linear model. However, over sloped terrain, the encountered incidence angle range increases. For example, a terrain slope of $20^{\circ}$ may increase an incidence angle range of $20-40^{\circ}$ to $0-60^{\circ}$ for which the linear approximation is not necessarily valid [7]. Van Doninck et al. [7] further showed that the mean values of difference in $R^{2}$ (coefficient of 
determination) of quadratic and linear fits increase with terrain slope. The variation of backscatter with incidence angle depends on scattering mechanisms and therefore on surface variables such as surface roughness and vegetation $[1,10,11]$. The dependence decreases with increasing surface roughness [9]. The regression line's intercept varies with liquid water content [5]. The parameters of a fitted linear model therefore vary with land cover type, and over time during unfrozen conditions. In order to establish a location specific model, a sufficient set of acquisitions with varying incidence angles (as available usually from overlapping orbits) are required. SAR data availability is, however, in many cases limited [12] and parameter derivation demands a certain processing effort in addition. A simpler method for the determination of the parameters of the linear model is therefore required for applications over large regions.

By excluding the effects of liquid water content, backscatter only depends on surface roughness and vegetation structure. This can be achieved by using acquisitions under frozen conditions. Frozen surface backscatter information can be used for a variety of applications. In Widhalm et al. [13], the minimum winter backscatter from Envisat Advanced Synthetic Aperture Radar (ASAR) data acquired in Global Mode (GM; $1 \mathrm{~km}$ resolution, C-band) was used for the derivation of surface roughness classes, which can be associated with different wetness levels typical for specific landcover types. It was shown that by using minimum winter backscatter values of the GM time series, vegetation physiognomy units of specific wetness regimes could be differentiated for the Arctic region north of the tree line. Further, Bartsch et al. [14] used GM frozen backscatter as a proxy for soil organic carbon. A so called 'dry reference' is also essential for the retrieval of relative soil moisture from radar data [5], which can be derived using frozen conditions. In these studies a pixel based approach for normalization was chosen and the linear model derived for the Arctic studies [13,14] based on an average of 46 ASAR GM acquisitions per location. ASAR GM does however only provide $1 \mathrm{~km}$ spatial resolution and higher spatial resolution is needed in order to capture the heterogeneity of Arctic environments [15]. It has been demonstrated that applications developed for GM can be transferred to data from ASAR operating in Wide Swath (WS) mode $(150 \mathrm{~m})$ and they can provide much higher detail and actual landscape patterns [14]. It is therefore expected that Sentinel-1, with a resolution of $93 \mathrm{~m} \times 87 \mathrm{~m}$ (range $\times$ azimuth) in EW GRDM (Extra Wide Swath, Ground Range Detected Medium Resolution) mode is of further benefit. Higher spatial resolution maps do however increase the processing and data storage effort in case of the pixel based normalization procedure.

In this study we demonstrate the applicability of a simplified normalization approach for winter (frozen surface) data in Arctic regions. We analyze the C-band backscatter dependency on incidence angle of various Arctic vegetation types in order to derive a universal normalization function for this region. This normalization method is then applied to demonstrate the applicability of a Sentinel-1 derived frozen surface map (sampled to $40 \mathrm{~m}$ ), as in the study of Widhalm et al. [13] where Envisat ASAR data acquired in Global Mode (sampled to $500 \mathrm{~m}$ ) was used.

\section{Material}

\subsection{Sentinel-1}

Sentinel-1 is an imaging radar mission which builds on ESA's ERS and Envisat instruments and thereby ensures continuity of C-band SAR data [16-18]. The mission is comprised of two satellites which fly in the same sun-synchronous, near-polar orbital plane with a $180^{\circ}$ orbital phase difference. Sentinel-1A was launched on the 3rd of April 2014 and Sentinel-1B on the 25th of April 2016. Each satellite has a repeat cycle of 12 days resulting in a revisit time (ascending and descending) of three days at the equator and less than one day in the Arctic. The SAR instrument operates at a centre frequency of $5.405 \mathrm{GHz}$ and radiometric accuracy is specified to lie within $1 \mathrm{~dB}(3 \sigma)[17,18]$. Sentinel-1 operates in four exclusive imaging modes with different resolution and coverage. To avoid conflicts operation modes are pre-programmed. Over land, the predefined mode is Interferometric Wide swath (IW), and over sea-ice and polar zones or certain maritime areas, the Extra Wide swath (EW) mode 
may be used to achieve wider coverage and better revisit time at lower geometric and radiometric resolution. The data of this study has been acquired in EW mode which is the standard over the Arctic Ocean. Acquisitions extend into the neighboring land areas which are characterized by tundra or the transition zone to the boreal biome. At incidence angles of $19-47^{\circ} \mathrm{EW}$ covers wide swaths of $400 \mathrm{~km}$ at a spatial resolution of $20 \mathrm{~m} \times 40 \mathrm{~m}$ and utilizes the TOPSAR technique (Terrain Observation with Progressive Scans SAR) using five sub-swaths. EW supports dual polarisation. Building upon the previous study of Widhalm et al. [13] which used Envisat ASAR GM HH data, we only use Sentinel-1 data acquired in $\mathrm{HH}$ polarization (horizontally transmitted and horizontally received). The data was obtained from the Sentinel data hubs as Level-1 Ground Range Detected Medium Resolution (GRDM) products, which consist of focused SAR data that has been detected, multilooked (mostly $6 \times 2$ looks) and projected to ground range using an Earth ellipsoid model [17]. Level-1 GRDM data in EW mode has a resolution of $93 \mathrm{~m} \times 87 \mathrm{~m}$ (range $\times$ azimuth) and a pixel spacing of $40 \mathrm{~m} \times 40 \mathrm{~m}$. Differences in available number of tracks over a certain location arise due to the predefined mission observation scenario.

\subsection{Envisat ASAR GM Frozen Surface Backscatter Dataset}

Comparisons were made with products from the predecessor of Sentinel-1 in order to assess the results. The minimum winter backscatter product by Widhalm et al. [13] is based on a seven year time series (2005-2011) of Envisat ASAR GM C-band data with $1 \mathrm{~km}$ resolution and is available for the entire terrestrial Arctic, north of the treeline. It is masked for lakes and glaciers based on GLWD [19] and GlobCover [20]. By comparing this frozen surface map to the Circumpolar Arctic Vegetation Map (CAVM, [21], see Section 2.4.4) it could be shown that the roughness and the vegetation's volume scattering provides the main influence on backscatter in the Arctic region, where wetter areas result in a lower backscatter. The Arctic region above the treeline can be differentiated into the classes 'wet', 'medium', 'dry' and 'other' (which represents flat surfaces or sandy soils). Furthermore, the vegetation classes of the CAVM can be divided into different wetness classes which were used to delineate backscatter thresholds. Further investigations by Bartsch et al. [14] showed that this minimum winter backscatter dataset could also be applied as a proxy to estimate soil organic carbon within the upper meter.

\subsection{Digital Elevation Models}

The 30 arc second resolution DEM GETASSE30 was used as basis for normalization across most sites. Its spatial resolution is comparably coarse but consistent across the Arctic. In order to assess the impact on parameterization, a TanDEM-X elevation model with $12 \mathrm{~m}$ spatial resolution (approximately 0.4 arc seconds) representing the covered vegetation zones was used. The available dataset encompasses one tile in northern Alaska (see Figure 1). For the mostly mountainous site of Zackenberg an available DEM of 3 arc second resolution was used [22].

\subsection{Land Cover Data and Focus Regions}

In order to analyze the land cover specific backscattering coefficient $\left(\sigma^{0}\right)$ incidence angle dependence and to investigate the applicability of the derived Sentinel-1 frozen surface maps, land cover datasets representing different locations around the Arctic were used (see Figure 1). They comprise classifications of optical satellite data (Landsat, AVHRR). Several additional regions have been selected for assessment of the results (comparison to ASAR GM). They vary regarding heterogeneity (abundance of lakes), vegetation and soils. All regions are areas with past and ongoing research studies linked to land cover [15]. Topographic gradients and mean number of tracks are provided in Table 1. 
Table 1. Mean $(\bar{s})$ and maximum $\left(s_{\max }\right)$ topographic gradients for calibration and evaluation sites based on the DEM GETASSE30 (resolution 30 arc seconds) and mean number of tracks per pixel $(\bar{t})$. Total number of ascending (\# Asc) and descending tracks (\# Desc) and total number of scenes per site (\# Scenes). $\star$ indicates validation sites. $\bullet$ for the Zackenberg site a higher resolution DEM ( 3 arc seconds) was eventually used [22]. $\diamond$ a TanDEM-X DEM (0.4 arc seconds) was additionally used for testing purposes within this region.

\begin{tabular}{ccccccc}
\hline & $\overline{\boldsymbol{s}}\left({ }^{\circ}\right)$ & $\left.\mathbf{s}_{\max } \mathbf{(}^{\circ}\right)$ & $\overline{\boldsymbol{t}}$ & \# Asc & \# Desc & \# Scenes \\
\hline Usa Basin $\star$ & 0.9 & 22.8 & 7.7 & 10 & 9 & 84 \\
Lena Delta $\star$ & 0.2 & 14.2 & 5.0 & 0 & 8 & 44 \\
Northern Alaska $\star \diamond$ & 4.0 & 34.3 & 4.9 & 13 & 9 & 82 \\
Zackenberg $\bullet$ & 6.0 & 31.8 & 11.7 & 11 & 2 & 66 \\
Kytalyk & 0.0 & 0.1 & 3.0 & 0 & 4 & 11 \\
East Canada Transect & 0.7 & 19.0 & 3.5 & 6 & 3 & 32 \\
Vaskiny Dachi & 0.3 & 1.8 & 10.8 & 7 & 7 & 90 \\
Shalaurovo & 0.9 & 2.8 & 3.0 & 0 & 3 & 15 \\
\hline
\end{tabular}

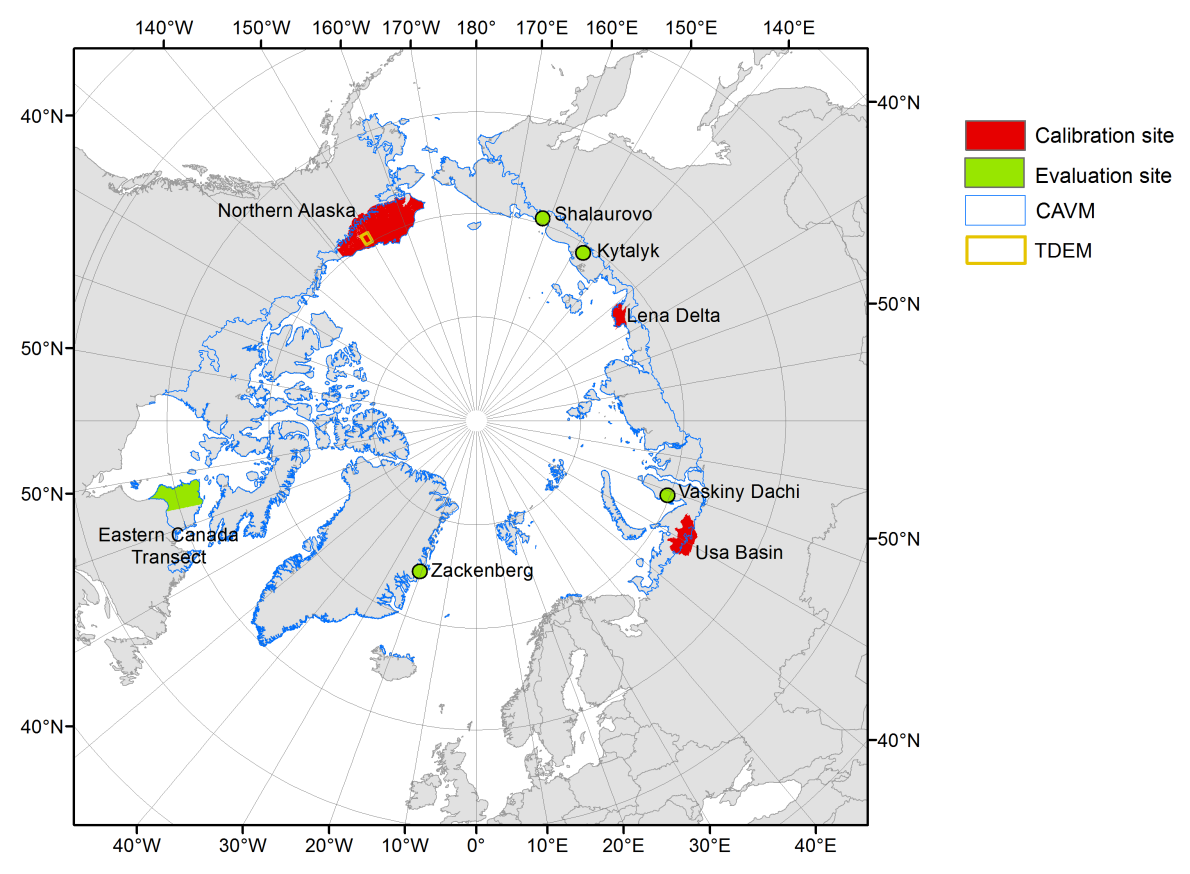

Figure 1. Overview of used calibration sites ([23-25], Usa Basin site extent restricted due to available coverage of Sentinel-1 EW data) and evaluation sites (extent of Zackenberg, Shalaurovo and Kytalyk sites as described in [15], Eastern Canada Transect and Vaskiny Dachi extents as defined in the project DUE GlobPermafrost [26] and southern border of the Circumpolar Arctic Vegetation Map (CAVM [21])) and extent of the CAVM and TanDEM-X DEM.

\subsubsection{Lena Delta}

The land cover map by Schneider et al. [23] covers the Lena River Delta in Northern Siberia, the largest Arctic delta. The classification is based on three Landsat 7 Enhanced Thematic Mapper (ETM+) images of July 2000 and 2001 (30 m resolution). Nine land cover classes characterized by their vegetation, surface moisture, and topography are differentiated using supervised classification. Nearly one third of the total area of the Lena Delta is occupied by water bodies. Together with wet and moist land cover classes, the wetland classes amount to over $70 \%$ of the Lena Delta area. 


\subsubsection{Usa Basin}

The land cover map by Virtanen et al. [24] covers the catchment area of the River Usa in north-eastern European Russia. Its vegetation zones cover taiga to forest-tundra and tundra to alpine regions. A semi-supervised classification method was applied to a mosaic of spectrally adjusted Landsat TM5 images (30 m resolution, July 2007) from five different dates using relatively sparse ground reference data. Some post classification refinements were implemented using additional GIS data.

\subsubsection{Ecosystems Map of Northern Alaska}

The Ecosystems map of Northern Alaska by Jorgenson and Heiner [25] (published 2003) is a map of local-scale ecosystems which combines vegetation structure from existing land cover maps with physiography, topography and bedrock characteristics. It covers Alaska north of the treeline and has a $30 \mathrm{~m}$ pixel resolution. The developed classification includes seven alpine, nine upland, five lowland, 10 riverine, four coastal, and one human-modified ecotypes.

\subsubsection{Circumpolar Arctic Vegetation Map}

The Circumpolar Arctic Vegetation Map (CAVM) is based on a false colour infrared image of 1993 and 1995 Advanced Very High Resolution Radiometer (AVHRR, $1 \mathrm{~km}$ resolution) data. The 1:7.5 M-scale CAVM is a GIS database which provides the first detailed circumpolar vegetation map of the Arctic tundra. It is derived by manual photo interpretation and infers vegetation information from expert knowledge of plant communities in relation to climate, parent material and topographic factors [21]. The CAVM is currently the only available circumpolar vegetation map, which provides sufficient and consistent thematic content for Arctic regions [15].

\subsubsection{Evaluation Sites}

The landscape of the Zackenberg study site in North East Greenland is mountainous with a broad, flat central valley. Water saturated areas are dominated by fens and gentle slopes are covered in grasslands. Drier patches of the valley are dominated by heath vegetation. Vegetation becomes sparser at higher elevations or is completely absent [27].

The Kytalyk site lies within the North East Siberian tundra. The site is characterized by three geomorphological units: preglacial Yedoma ice-complex remnants, alas lowlands, and a river floodplain. Alas is a location specific term for thermokarst depressions in Yakutia. The area of the Yedoma remnants is dominated by well-drained tussock and non-tussock tundra. The alas plain is characterized by low-centered polygons, where wet Sphagnum and sedge fen are covering the polygon centers and dwarf shrub fens vegetate the dry elevated polygon rims and irregular frost mounds. The river floodplain holds areas overgrown by Salix bushes (up to $2 \mathrm{~m}$ high) and sparsely vegetated sediments [28].

The Vaskiny Dachi research station in the center of the Yamal Peninsula is located in a landscape of highly-dissected alluvial-lacustrine-marine plains and terraces dominated by tundra lakes and river flood plains [29]. The watersheds are characterized by dense dwarf shrubs. Dwarf shrub-moss-lichen communities occupy the well-drained hilltops and willow thickets can be found in river valleys or landslide cirques. Furthermore sedge and sphagnum bogs can be found in river valley bottoms and other depressions [30].

The Shalaurovo study site in North East Siberia is located in the southern tundra. Well drained upland vegetation is characterized by shrubby tussock moss tundra, while gentle sloped areas are dominated by shrubby grass tundra. Creeks and depressions are vegetated by willow moss communities and sedge moss fens [27].

The Eastern Canada Transect is characterized by herbaceous Arctic tundra in the most northern part and shrubby Arctic tundra down to the northern tree line [31]. The shrub tundra features lichens, 
birch and willow shrubs, while the herbaceous tundra is characterized by grass and some willow and heath shrubs [32]. The landscape is dominated by an abundance of lakes and rivers and vast areas of rugged terrain [33].

\section{Methodology}

The backscattering coefficient $\sigma^{0}$ is strongly influenced by the incidence angle. Since $\sigma^{0}$ incidence angle dependence is controlled by surface parameters like topography, soil surface roughness and vegetation cover [1,10], different land cover types exhibit varying $\sigma^{0}$ angular signatures. Due to the increasing influence of the incidence angle with decreasing surface roughness, the angular variations of $\sigma^{0}$ are more pronounced for sparse vegetation and bare surfaces [34].

Higher soil moisture causes a rise in backscatter amount due to its influence on the dielectric properties [35]. As described in Section 2.2, in Arctic regions backscatter is dominated by the influence of surface roughness and vegetation structure rather than dielectric properties. Frozen ground has backscatter values similar to dry soils. By using winter acquisitions the values only depend on surface roughness, vegetation and snow cover, and the influence of soil moisture can be omitted. The influence of dry snow on C-band radar data can be neglected (e.g., [36]). The assumption is that specific land cover types in the Arctic, as usually determined by optical data in local studies, exhibit a characteristic backscatter level (limited range) under frozen conditions.

We processed Sentinel-1 EW GRDM data of selected Arctic regions (see Figure 1) to examine $\sigma^{0}$ angular signatures of Sentinel-1 across the Arctic. To enable a comparison to previously used normalization methods applied in Widhalm et al. [13], we processed the data for the month December (2014, 2015 and 2016). It has been shown in many studies that the ground can be identified as frozen with radar data in high latitudes during this period (e.g., [36-38]). ESA's Sentinel Application Platform (SNAP 5.0) was used for processing. The data was calibrated, terrain corrected and sampled to a resolution of $40 \mathrm{~m}$ using the Range-Doppler Terrain Correction and the DEM GETASSE30 (resolution 30 arc seconds; see Figure 2). For the mountainous Zackenberg site an available higher resolution local DEM was used. In order to validate the applicability of the 30 arc second DEM GETASSE30 in combination with the higher resolution Sentinel-1 data, we compared regression results obtained from data incorporating GETASSE30 and the high resolution DEM (12 $\mathrm{m}$ spatial resolution) based on TanDEM-X. The test was performed over a subsection $\left(148^{\circ} \mathrm{W}-150^{\circ} \mathrm{W}, 69^{\circ} \mathrm{N}-70^{\circ} \mathrm{N}\right)$ within the Northern Alaska study site, where a sufficient range of different vegetation types existed. To exclude border noise, areas of 85 pixels in width have been removed at the edges.

In a first step, the standard pixel based local incidence angle (LIA) linear relationship derived from the multi-annual record (with overlapping orbits) was determined for selected sites. This is referred to in the following as the 'pixel based approach'.

In a second step, the dependence of $\sigma^{0}$ on incidence angle variations for the Arctic land cover types was investigated. We analyzed $\sigma^{0}$ (in $\mathrm{dB}$ ) and local incidence angle for land cover classes of all three Arctic land cover maps used for calibration (Lena Delta, Usa Basin and Northern Alaska; in total 56 samples). They represent a range of land cover classes, flat to moderate terrain and areas with 4.9 to 7.7 mean number of tracks per pixel (Table 1). The latter allows for coverage of varying incidence angles in the samples. The EW data was resampled to the $30 \mathrm{~m}$ resolution of the landcover maps. Furthermore we separated the land cover classes into groups of estimated vegetation height (see Table 2) and examined the scatter of slope and $\sigma^{0}$ values at $30^{\circ}$ incidence angle for these groups of vegetation height. We fitted linear functions to the data of each land cover class (backscatter versus local incidence angle) and inferred a function, which could then further be used to normalize the data to a reference angle of $30^{\circ}$ :

$$
\sigma^{0}\left(30^{\circ}\right)=\sigma^{0}(\theta)-k *\left(\theta-30^{\circ}\right)
$$

where $\theta$ is the local incidence angle and $k$ the slope derived by the delineated function. This method is referred to as the 'slope approach'. 
Table 2. Regression parameters ( $k$-slope and $d$-intercept), height characterization and merged classes of land cover classes used for slope function derivation.

\begin{tabular}{|c|c|c|c|c|c|}
\hline Landcover Class & $k$ & $d$ & $\mathbf{R}^{2}$ & Height & Merged Class \\
\hline $\begin{array}{l}\text { Usa Basin } \\
\text { Spruce forest } \\
\text { Pine forest } \\
\text { Mixed forest } \\
\text { young stands } \\
\text { Willow-complexes } \\
\text { Meadows } \\
\text { Bog shrubland } \\
\text { Open bogs } \\
\text { Wetlands } \\
\text { Shrub-moss tundra } \\
\text { Dwarf birch tundra } \\
\text { Shrub-lichen tundra } \\
\text { dry tundra with some bare peat } \\
\text { sparse alpine tundra } \\
\text { bare land } \\
\text { anthropogenic } \\
\text { human impacted tundra-shrublands }\end{array}$ & $\begin{array}{l}-0.08 \\
-0.16 \\
-0.09 \\
-0.09 \\
-0.12 \\
-0.12 \\
-0.12 \\
-0.14 \\
-0.16 \\
-0.14 \\
-0.13 \\
-0.16 \\
-0.16 \\
-0.12 \\
-0.07 \\
-0.13 \\
-0.10\end{array}$ & $\begin{array}{l}-8.81 \\
-7.82 \\
-8.67 \\
-8.54 \\
-8.16 \\
-7.58 \\
-8.39 \\
-8.45 \\
-8.05 \\
-8.96 \\
-9.19 \\
-8.78 \\
-8.77 \\
-8.83 \\
-8.79 \\
-7.25 \\
-9.47\end{array}$ & $\begin{array}{l}0.11 \\
0.22 \\
0.12 \\
0.11 \\
0.17 \\
0.19 \\
0.17 \\
0.21 \\
0.24 \\
0.22 \\
0.21 \\
0.25 \\
0.27 \\
0.12 \\
0.03 \\
0.09 \\
0.15\end{array}$ & $\begin{array}{l}\text { high } \\
\text { high } \\
\text { high } \\
\text { high } \\
\text { high } \\
\text { medium } \\
\text { medium } \\
\text { low } \\
\text { low } \\
\text { medium } \\
\text { medium } \\
\text { medium } \\
\text { low } \\
\text { other } \\
\text { other } \\
\text { other } \\
\text { other }\end{array}$ & $\begin{array}{l}\text { wet sedge/wetland } \\
\text { wet sedge/wetland } \\
\text { low/dwarf shrub tundra } \\
\text { low/dwarf shrub tundra } \\
\text { low/dwarf shrub tundra }\end{array}$ \\
\hline $\begin{array}{l}\text { Northern Alaska } \\
\text { Coastal Barrens } \\
\text { Coastal Wet Sedge Tundra } \\
\text { Coastal Grass \& Dwarf Shrub Tundra } \\
\text { Riverine Dryas Dwarf Shrub Tundra } \\
\text { Riverine Barrens } \\
\text { Riverine Low Willow Shrub } \\
\text { Riverine Moist Sedge Shrub } \\
\text { Riverine Wet Sedge Tundra } \\
\text { Riverine Spruce-Balsam Poplar Forest } \\
\text { Riverine Balsam Poplar Forest } \\
\text { Riverine Spruce Forest } \\
\text { Riverine Tall Alder-Willow Scrub } \\
\text { Lowland Wet Sedge Tundra } \\
\text { Lowland Moist Sedge Tundra } \\
\text { Lowland Low Birch-Willow Shrub } \\
\text { Lowland Spruce Forest } \\
\text { Upland Birch-Aspen Forest } \\
\text { Upland Tussock Tundra } \\
\text { Upland Dryas Dwarf Shrub Tundra } \\
\text { Upland Shrubby Tussock Tundra } \\
\text { Upland Low Birch-Willow Shrub } \\
\text { Upland Moist Sedge Shrub } \\
\text { Upland Birch-Aspen-Spruce Forest } \\
\text { Upland Spruce Forest } \\
\text { Upland Tall Alder Shrub } \\
\text { Alpine Carbonate Barrens } \\
\text { Alpine Mafic Barrens } \\
\text { Alpine Non-Carbonate Dryas Dwarf Shrub } \\
\text { Alpine Carbonate Dryas Dwarf Shrub } \\
\text { Alpine Mafic Dryas Dwarf Shrub }\end{array}$ & $\begin{array}{l}-0.24 \\
-0.23 \\
-0.22 \\
-0.08 \\
-0.18 \\
-0.17 \\
-0.18 \\
-0.21 \\
-0.17 \\
-0.16 \\
-0.07 \\
-0.10 \\
-0.24 \\
-0.23 \\
-0.15 \\
-0.17 \\
-0.08 \\
-0.18 \\
-0.13 \\
-0.15 \\
-0.12 \\
-0.13 \\
-0.07 \\
-0.09 \\
-0.07 \\
-0.06 \\
-0.14 \\
-0.09 \\
-0.07 \\
-0.14\end{array}$ & $\begin{array}{l}-8.78 \\
-8.37 \\
-7.76 \\
-8.72 \\
-6.67 \\
-6.20 \\
-7.48 \\
-7.17 \\
-6.01 \\
-5.83 \\
-8.85 \\
-7.66 \\
-6.70 \\
-6.52 \\
-8.34 \\
-5.91 \\
-8.14 \\
-7.38 \\
-7.65 \\
-8.32 \\
-8.85 \\
-8.80 \\
-8.82 \\
-8.18 \\
-8.18 \\
-5.73 \\
-5.13 \\
-8.39 \\
-6.44 \\
-5.40\end{array}$ & $\begin{array}{l}0.27 \\
0.31 \\
0.31 \\
0.08 \\
0.17 \\
0.29 \\
0.24 \\
0.25 \\
0.31 \\
0.38 \\
0.07 \\
0.14 \\
0.40 \\
0.46 \\
0.23 \\
0.43 \\
0.08 \\
0.37 \\
0.10 \\
0.26 \\
0.15 \\
0.15 \\
0.07 \\
0.11 \\
0.07 \\
0.04 \\
0.18 \\
0.07 \\
0.04 \\
0.19\end{array}$ & $\begin{array}{c}\text { low } \\
\text { low } \\
\text { medium } \\
\text { medium } \\
\text { other } \\
\text { medium } \\
\text { medium } \\
\text { low } \\
\text { high } \\
\text { high } \\
\text { high } \\
\text { medium } \\
\text { low } \\
\text { low } \\
\text { medium } \\
\text { high } \\
\text { high } \\
\text { medium } \\
\text { medium } \\
\text { medium } \\
\text { medium } \\
\text { medium } \\
\text { high } \\
\text { high } \\
\text { medium } \\
\text { other } \\
\text { other } \\
\text { medium } \\
\text { medium } \\
\text { medium }\end{array}$ & $\begin{array}{c}\text { low / dwarf shrub tundra } \\
\text { moist sedge/shrub } \\
\text { wet sedge/wetland } \\
\text { Forest } \\
\text { Forest } \\
\text { Forest } \\
\\
\text { wet sedge/wetland } \\
\text { moist sedge/shrub } \\
\text { low / dwarf shrub tundra } \\
\text { Forest } \\
\text { Forest } \\
\text { tussock tundra } \\
\text { low / dwarf shrub tundra } \\
\text { tussock tundra } \\
\text { low / dwarf shrub tundra } \\
\text { moist sedge/shrub } \\
\text { Forest } \\
\text { Forest }\end{array}$ \\
\hline $\begin{array}{l}\text { Lena Delta } \\
\text { Mainly non-vegetated areas } \\
\text { Dry moss-, sedge-, and dwarf shrub-dominated tundra } \\
\text { Wet, sedge- and moss-dominated tundra } \\
\text { Dry, grass-dominated tundra } \\
\text { Moist grass- and moss-dominated tundra } \\
\text { Moist to dry dwarf shrub-dominated tundra } \\
\text { Dry tussock tundra }\end{array}$ & $\begin{array}{l}-0.30 \\
-0.23 \\
-0.20 \\
-0.21 \\
-0.19 \\
-0.20 \\
-0.19\end{array}$ & $\begin{array}{l}-6.84 \\
-7.74 \\
-7.93 \\
-7.61 \\
-7.85 \\
-7.34 \\
-7.68\end{array}$ & $\begin{array}{l}0.44 \\
0.51 \\
0.37 \\
0.37 \\
0.46 \\
0.39 \\
0.46\end{array}$ & $\begin{array}{l}\text { low } \\
\text { low } \\
\text { low } \\
\text { low } \\
\text { low } \\
\text { medium } \\
\text { medium }\end{array}$ & $\begin{array}{l}\text { non-vegetated/coastal } \\
\text { wet sedge/wetland }\end{array}$ \\
\hline
\end{tabular}




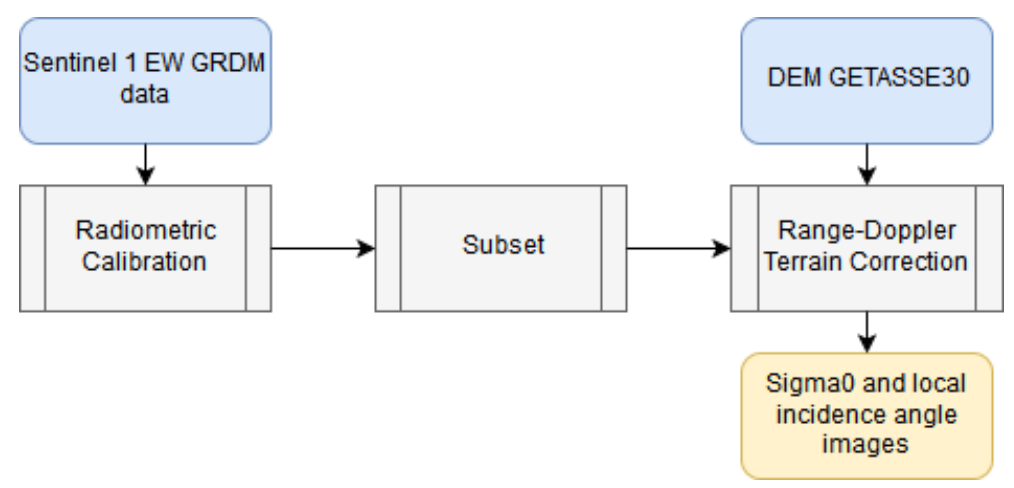

Figure 2. Flowchart of the performed pre-processing steps.

The pixel and slope approach were eventually compared in order to test the validity of the new method. The test is performed over the Usa basin area as well as on central Yamal, an area outside of the calibration region. The backscatter minimum was calculated in both cases from all available images of Sentinel-1A of December 2016 in accordance with potential applications. Coverage at the Vaskiny Dachi site was 24 to 30 images and at the Usa site 18 to 24 images.

Additionally, we investigated the applicability of a Sentinel-1 frozen surface map derived from slope function normalized data. Based on Widhalm et al. [13], we calculated the minimum and lower 10th percentile of the normalized Sentinel-1 time series. Data from single and multiple years are assessed in order to evaluate the impact of effects such as rain on snow. We compared our results to the ASAR GM map [13] and applied the same coarse water body masking. The comparison to the circumpolar vegetation database used in Widhalm et al. [13] was made over selected regions including the evaluation sites (see Section 2.4.5) as well as the calibration regions.

\section{Results}

\subsection{Normalization}

We calculated the regression lines for $\sigma^{0}$ and incidence angle for all 56 land cover classes of our calibration sites (Lena Delta, Usa Basin and Northern Alaska). Figure 3 shows classes of all three sites which have been combined into six common classes for visualization purposes. The spread is most pronounced for the forest class, where classes of different tree species are combined. As expected forests show lowest dependency on incidence angle and highest $\sigma^{0}$ values, while non-vegetated or plain coastal areas exhibit great variations with incidence angle and very low $\sigma^{0}$ values. The dependency on vegetation height can be seen in Figure 4. It can be exemplified that classes of shorter vegetation are characterized by high absolute slope values and low backscatter, while for taller vegetation the opposite applies. For the Lena Delta the incidence angle dependency was more pronounced than for the Usa Basin (see Figure 4). Absolute slope values are higher in the Lena Delta with an extreme value of -0.3 for 'mainly non-vegetated areas' (see Table 2). These higher absolute slope values are associated with lower backscatter values. $\sigma^{0}$ values are higher in the Usa Basin area, which comprises various forest classes. For example, spruce forest exhibits a slope value of -0.08 . As the site of Northern Alaska covers flat coastal areas as well as forest regions, slope and $\sigma^{0}$ values are widely spread with high backscatter values and minimal absolute slope values for alpine areas, and low backscatter and maximal absolute slope values for flat coastal regions. The test with the higher spatial resolution TanDEM-X DEM over the North Slope gave similar results. Mean and maximum topographic gradients were $0.8^{\circ}$ and $9.9^{\circ}$ for GETASSE30 and $1.7^{\circ}$ and $48.9^{\circ}$ for the high resolution DEM. The resulting regression lines showed a low RMS difference of 0.004 ( $2 \%$ of the total range) for slope values and 0.2 ( $5 \%$ of the total range) for intercept values. Consequently, it was assumed that errors of diverging incidence angles, due to a coarser DEM, are negligible in this case and that the derived parameters are valid for moderate terrain (see Figure 5). 


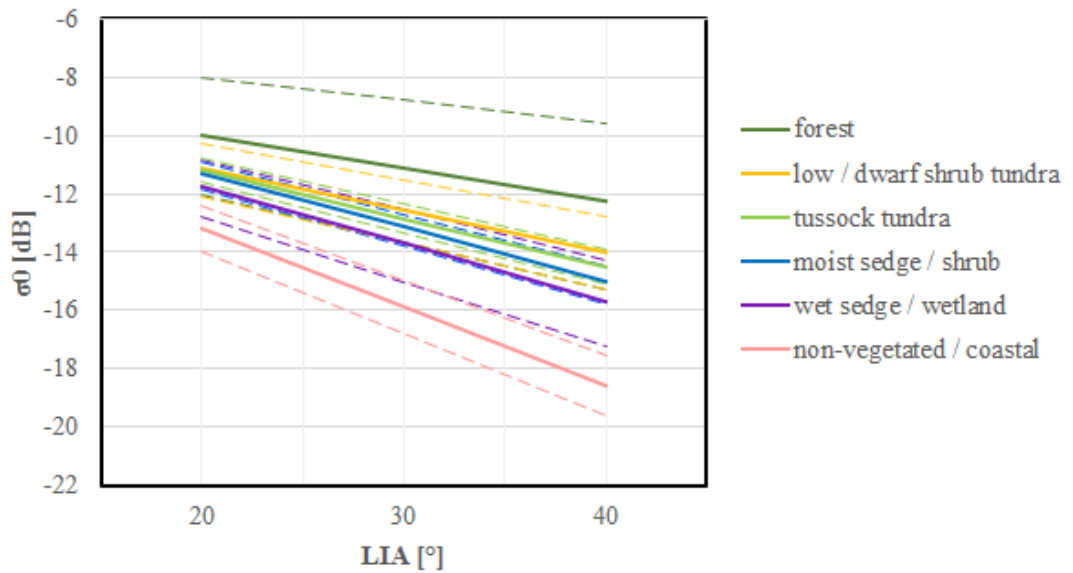

Figure 3. Regression lines for $\sigma^{0}$ and local incidence angles of various vegetation types. Regression lines have been derived from data of land cover classes of the sites Lena Delta, Usa Basin and Northern Alaska. The results of all sites have been merged into six combined classes. 1st and 3rd quartile lines are depicted as dashed lines.
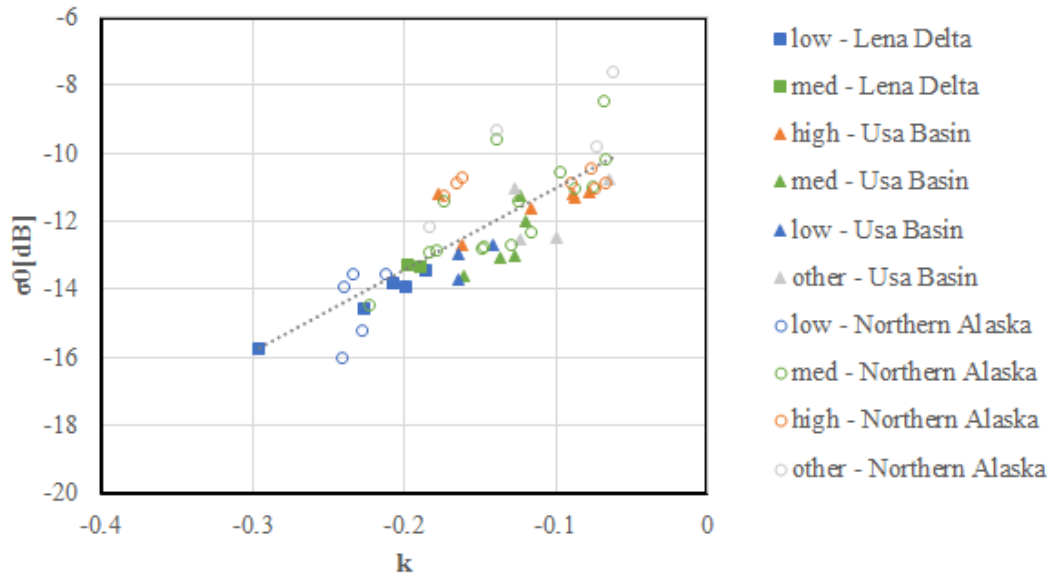

Figure 4. Scatterplot of slope and $\sigma^{0}$ values at $30^{\circ}$ incidence angle for the sites Lena Delta, Usa Basin and Northern Alaska (depicted in different shapes), with differentiation of approximate vegetation height of land cover classes (depicted in different colors).
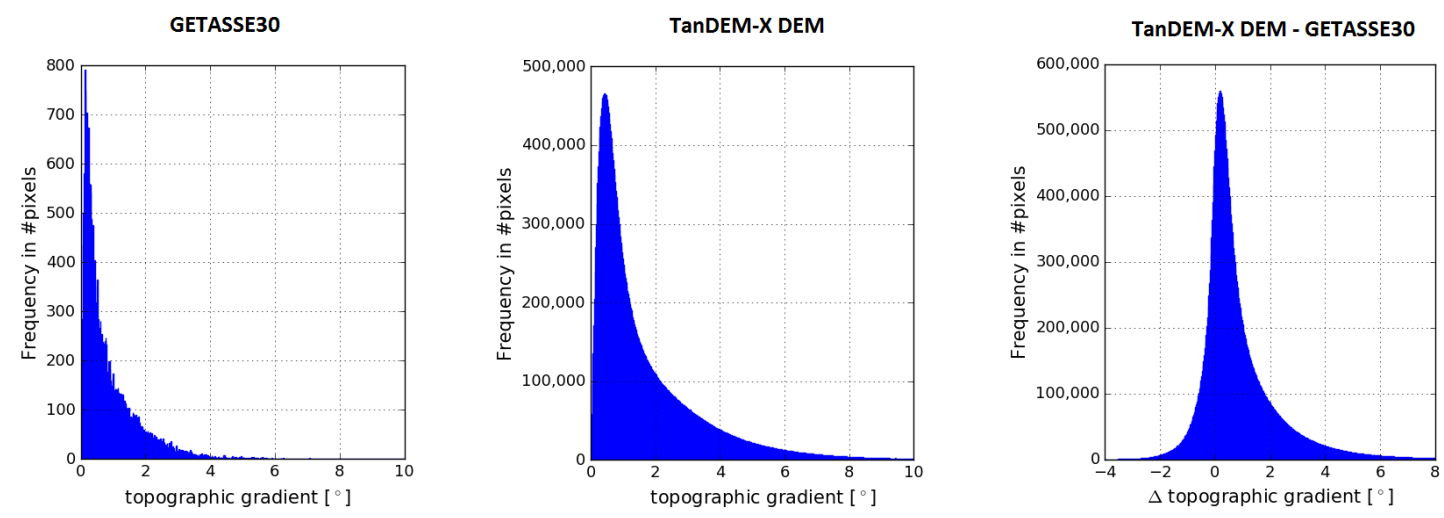

Figure 5. Histograms of topographic gradients for GETASSE30 and TanDEM-X DEM of the same area (see Figure 1) and histogram of differences in topographic gradient for TanDEM-X DEM-GETASSE30. 
A linear relation between slope and backscatter is apparent (Figure 4). The $\mathbf{R}^{2}$ between $k$ and $\sigma^{0}{ }_{30}$ is 0.64 . We therefore delineate the following equation to calculate the slope based on given backscatter and local incidence angle values:

$$
k=\left(\sigma^{0}(\theta)+8.618\right) /(\theta-5.978)
$$

with $\theta$ being the local incidence angle and $k$ the slope.

We then compared the results of the slope function based normalization to those of the 'pixel based approach' where slope values have been calculated for each pixel separately based on a time series considering multiple tracks. Figure 6 shows the results for two regions. The minimum images of the available time series show good agreements for both approaches with mean differences of $-0.1 \mathrm{~dB}$ for the Vaskiny Dachi site. Some disagreements can be found in the Usa Basin area in mountainous regions (Eastern part) with differences of more than $40 \mathrm{~dB}$.

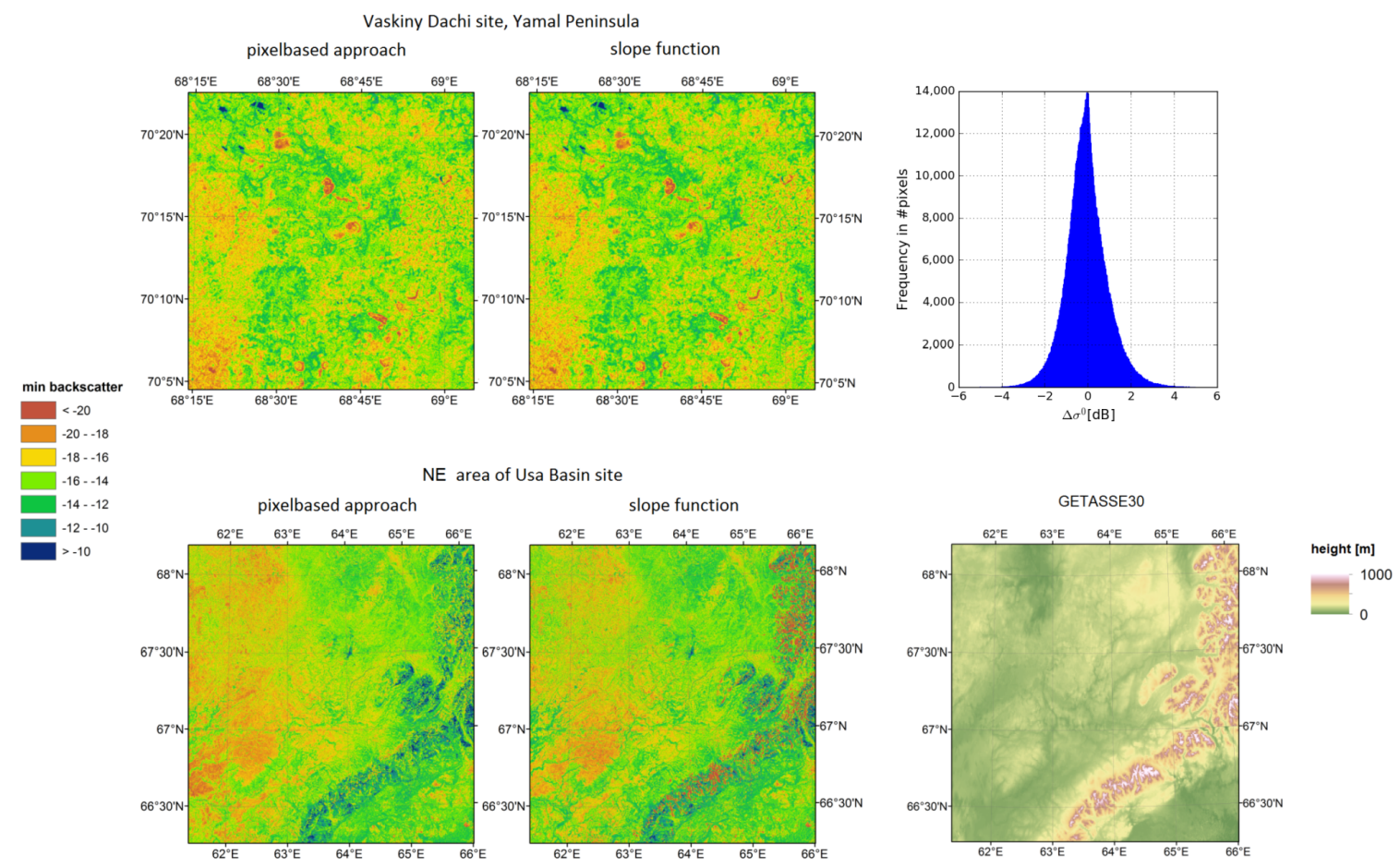

Figure 6. Comparison of minimum backscatter images of a timeseries derived from pixelbased normalization (left) versus normalization with slope function (middle) for two different areas (top: region surrounding the Vaskiny Dachi field station on central Yamal; bottom: region surrounding Vorkuta at the northeast Usa Basin site); top right: Histogram for difference of pixel-based minus slope function-based normalization approach (mean $=-0.1 \mathrm{~dB}, \mathrm{std}=1.0 \mathrm{~dB}$ ); bottom right: DEM GETASSE30 of northeast Usa Basin site.

\subsection{Sentinel-1 Frozen Surface Backscatter Statistics}

As the normalization with the slope function seemed to sufficiently match the results of the established pixel based approach, we further investigated the applicability of a Sentinel-1 based frozen surface map using slope function normalized images. When comparing minimum winter images as used for the map delineation in [13], it became apparent that the results seemed to be dependent on the number of data sets that were used in the calculation of the minimum backscatter image. Using a higher number of datasets leads to lower minimum backscatter images. This effect could be reduced by using the 10th percentile instead of the minimum (see Figure 7). The difference between 
the minimum images of one and three years is $1.14 \mathrm{~dB}$, while when using the percentile the difference reduces to $0.34 \mathrm{~dB}$.

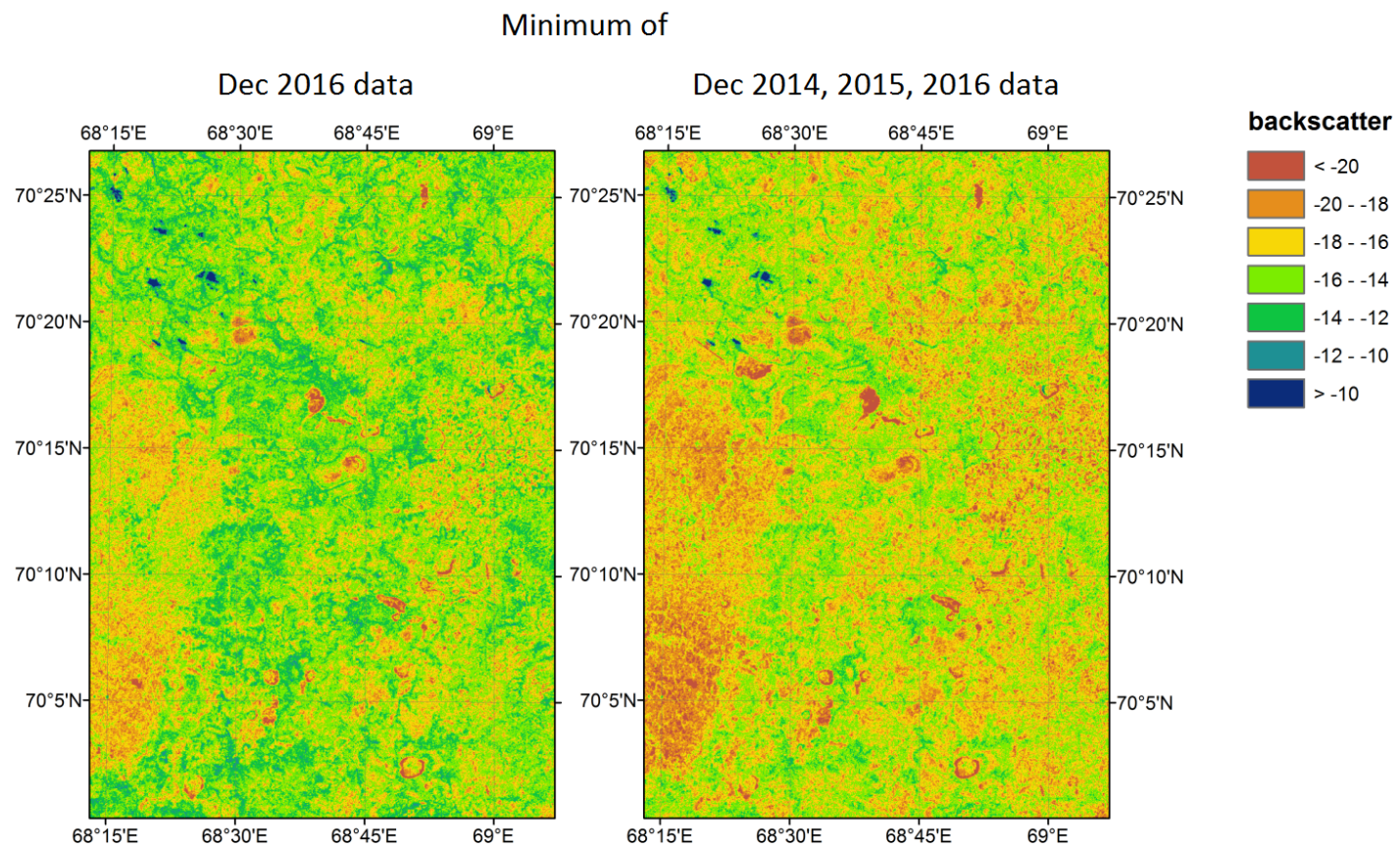

10th Percentile of
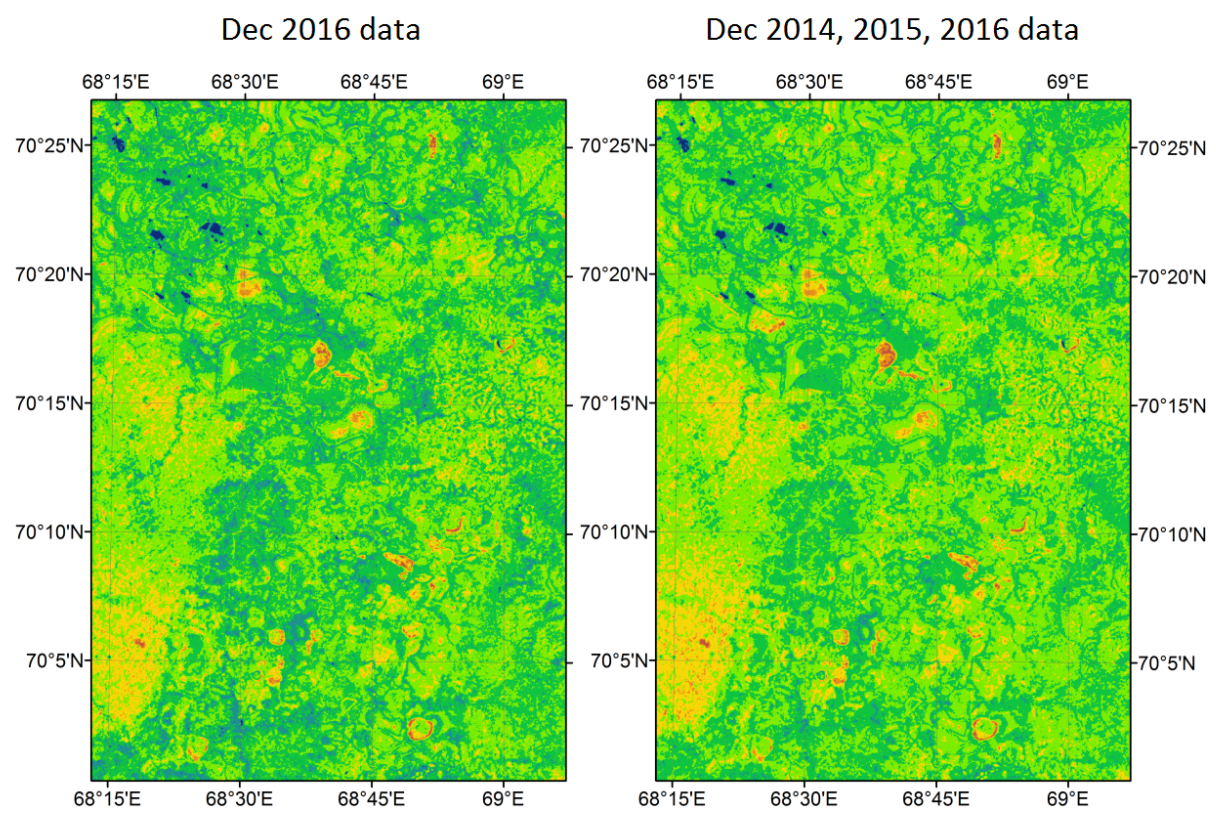

Figure 7. Top: minimum backscatter and bottom: 10th percentile of the December 2016 timeseries (left) and December 2016, 2015 and 2016 timeseries (right) of the area surrounding the Vaskiny Dachi field station on central Yamal.

A comparison with the Circumpolar Arctic Vegetation Map (CAVM), which was also used to delineate the thresholds in [13], clearly showed lower values for wet classes than for drier ones within each region (Figure 8). Nevertheless, a common threshold that could be applied over all areas could 
not be derived, due to inconsistencies especially within the moist classes, where different regions showed varying median values for the same CAVM classes. Furthermore dry classes were very scarce within the selected sites with a negligibly low sample size.

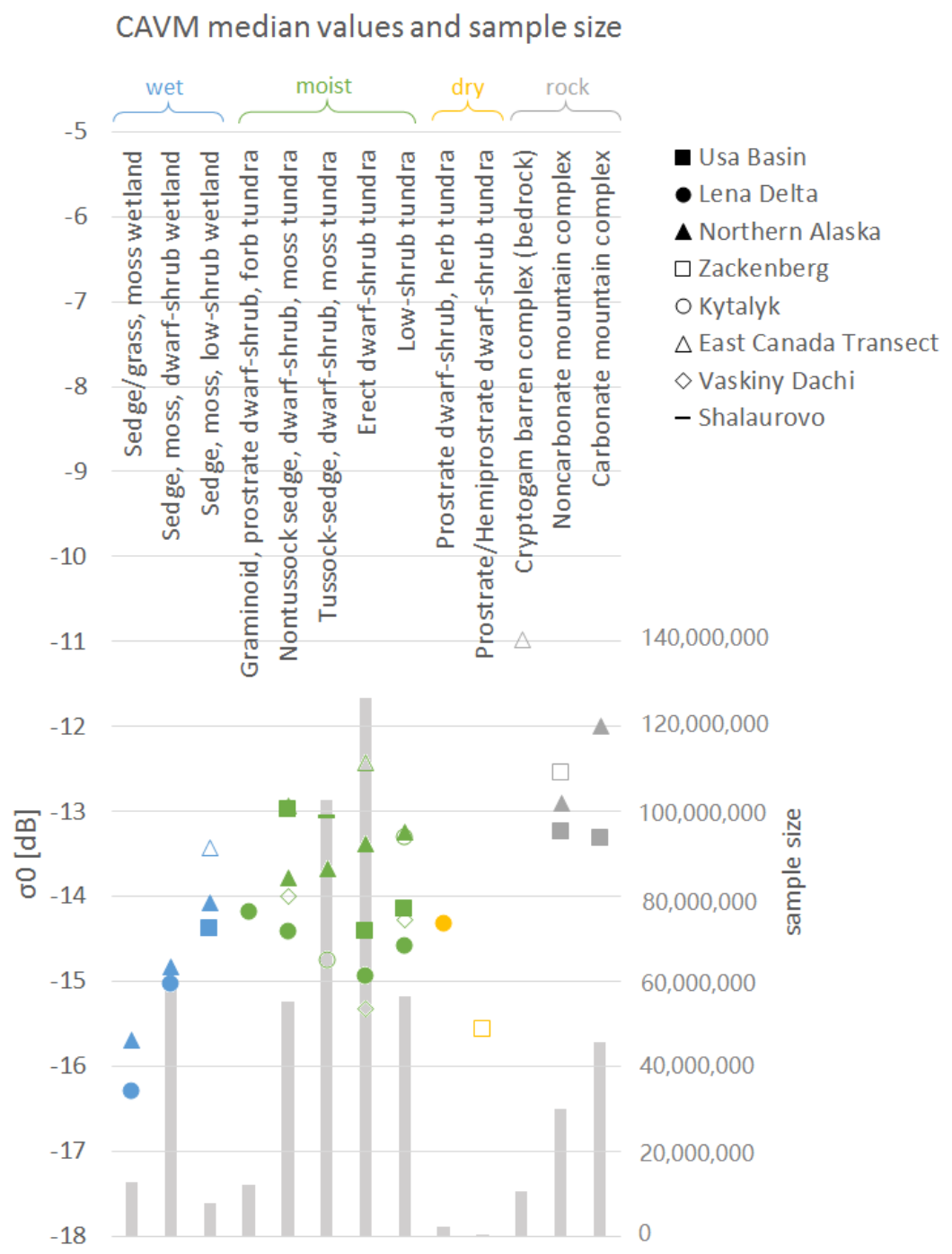

Figure 8. Median values of the 10th percentile maps for CAVM (Circumpolar Arctic Vegetation Map) classes of various study regions. CAVM classes are classified as wet, moist, dry and rock (moisture classes according to [39]). The sample size of each class, combined for all regions, is displayed by bars.

Comparing our Sentinel-1 frozen ground percentile and minimum backscatter maps to the minimum backscatter maps of Envisat ASAR GM reveals that differences vary depending on study site (see Figure 9). We calculated differences between median values of Envisat ASAR GM minimum maps and Sentinel-1 percentile maps for each site. The differences range from 0.4 to $2.5 \mathrm{~dB}$ with higher values for Sentinel-1. The Lena Delta and Northern Alaska site both show higher differences, while at the Usa Basin site Sentinel-1 values match those of Envisat ASAR GM to a greater extent. Median backscatter values for Sentinel-1 percentile maps are similar for Northern Alaska and Usa Basin with $-13.4 \mathrm{~dB}$ and $-13.8 \mathrm{~dB}$ respectively. However, Envisat ASAR GM median values are much lower for Northern Alaska with $-15.9 \mathrm{~dB}$ compared to $-14.2 \mathrm{~dB}$ at the Usa Basin. The lowest Sentinel-1 and Envisat ASAR GM values were found in the Lena Delta $(-14.8 \mathrm{~dB}$ and $-17.2 \mathrm{~dB})$. 

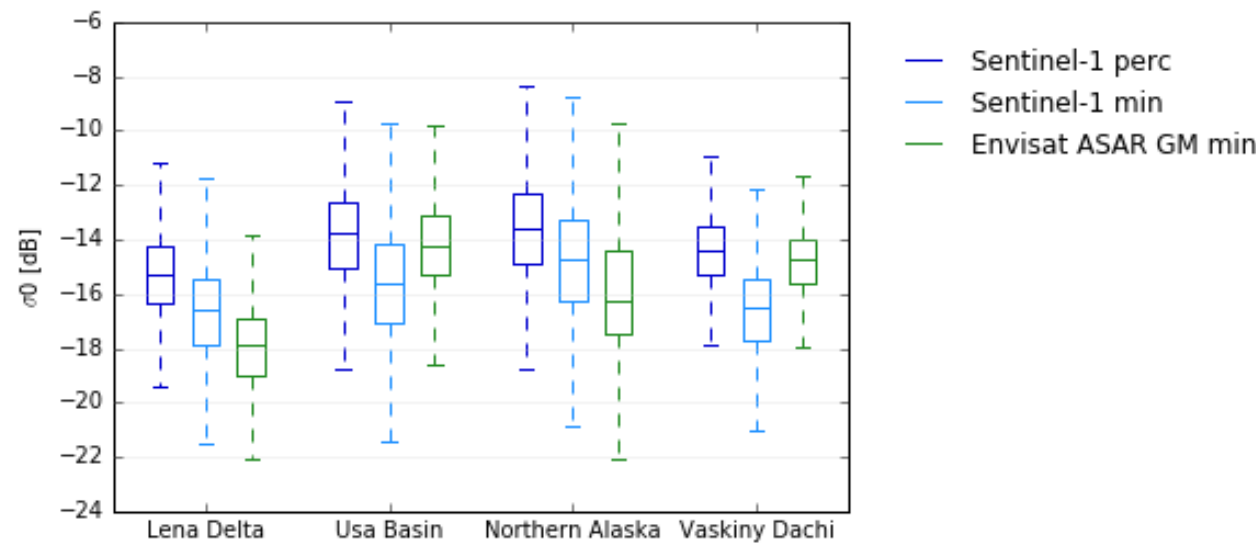

Figure 9. Boxplots of the 10th percentile (perc) and minimum (min) maps of Sentinel 1 and of the minimum maps of Envisat ASAR GM for the sites Lena Delta, Usa Basin, Northern Alaska and Vaskiny Dachi.

\section{Discussion}

\subsection{Normalization}

The analysis of $\sigma^{0}$ and local incidence angle scatterplots of various land cover classes illustrates an adequate linear dependence for the existing incidence angle range in most cases. $R^{2}$ values shown in Table 2 are naturally lower for smaller slopes. Although the relationship between backscatter and incidence angle were naturally not linear [1], previous studies affirm our findings and show the applicability of a linear fit for certain incidence angle ranges $[7,9,10]$. In Figure 3 the effect of different vegetation and land cover types on angular signatures is apparent. This is explained by its dependence on scattering mechanisms, and consequently, surface variables such as surface roughness and vegetation $[1,10,11]$. The comparison between plain coastal regions, like the Lena Delta and northern parts of the Alaska site, and areas with higher vegetation such as the Usa Basin site and forested zones of the Alaska site, clearly showed a higher influence of incidence angle with classes of lower vegetation and smoother surfaces. As incidence angle dependence increases with decreasing surface roughness [9], it is no surprise to find the highest absolute slope values and therefore highest angular dependence for coastal barrens in Alaska and mainly non-vegetated areas like sandbanks in the Lena Delta.

Since surface roughness and vegetation cover not only influence the backscatter's dependence on incidence angle, but also the backscatter amount itself [1], higher absolute slope values are mostly found for land cover classes with lower backscatter values. Since we only used winter data in this study and frozen soils show similar backscatter values to dry soils, the effect of soil moisture on backscatter can be excluded [36-38]. Therefore with constant sensor parameters, like frequency and polarization, variations in backscatter amount can only be caused by surface roughness and vegetation structure, which remain constant over winter. Due to these mutual dependencies, a linear relationship between $\sigma^{0}$ at a constant local incidence angle, and slope could be derived (see Figure 4). In Figure 4 again the influence of vegetation height becomes apparent, with low vegetation classes showing low backscatter values in combination with high absolute slope values in contrast to higher vegetation.

Equation (2) permits the slope to be calculated for each pixel and each image depending on backscatter amount and local incidence angle. As is done in previous normalization approaches [5,7,40], the acquisitions can be normalized to a common incidence angle by utilizing Equation (1). We calculated minimum backscatter images using slope function normalized images of December 2016. We then compared them to results where the normalization that has been performed using the pixel based approach of employing slope values, which were calculated based on the backscatter and incidence angle time series for each individual pixel. The results revealed hardly any differences for the Vaskiny 
Dachi site in the central Yamal Peninsula, which is characterized by a gentle relief. However, some deviations were apparent for another site. This second area, which is located around the city Vorkuta at the Usa River, includes the northern part of the Ural mountains. In these mountainous locations distinct differences could be found. As Van Doninck et al. [7] pointed out, in the case of steep slopes, the incidence angle range exceeds that for which the linear approach of the angular dependence is valid. Steep slopes could be found within the sites of Usa Basin at the bordering Ural mountains, for the Brooks Range in Northern Alaska and the mountainous Zackenberg site. Due to the use of the coarser resolution DEM GETASSE30, misregistrations may have occurred for mountainous regions. However, as a linear normalization approach is not suitable for these areas, results can be expected to be erroneous independent on the DEM's resolution.

\subsection{Sentinel-1 Frozen Surface Backscatter Statistics}

Changes in snow structure can cause backscatter to increase during winter in C-band [37]. To avoid this influence, as well as exclude rain on snow events [41], the minimum winter backscatter from Envisat ASAR GM was calculated in Widhalm et al. [13]. To test the applicability of a Sentinel-1 frozen surface map based on Widhalm et al. [13], we calculated the minimum backscatter images of December time series of slope function normalized images. Investigations revealed a dependency of minimum backscatter values on the number of scenes used in the calculation, with the values clearly decreasing when more scenes from different years were incorporated. This may be caused by the speckled nature of SAR images, whereby an interference caused by numerous scatterers within each resolution cell induces a noise-like effect. Alternatively, the coarse spatial resolution elevation model implemented here for co-registration and slope retrieval may also introduce noise. By using the 10th percentile rather than the minimum, resulting outliers could be avoided, leading to a more stable product, which is less affected by the number of scenes used in the calculation.

The land cover maps used in this research cover a wide range of years. Changes may have occurred over this time period, like for instance in areas of gas and oil extraction [42]. This leads to an increase of urban settlements and locally double bounce effects, respectively, which are currently not considered. These areas may need to be treated separately before further application.

A comparison of our Sentinel-1 frozen ground maps to those of Envisat ASAR GM reveals differences between study sites. As we used the 10th percentile for our Sentinel-1 product instead of the minimum, higher backscatter values than for Envisat ASAR GM were expected. However, a constant offset was not apparent. The inconsistent differences could have many causes. For one, the used timespan is not the same for both sensors (2005-2011 for Envisat ASAR GM and 2014-2016 for Sentinel-1), which could lead to differences related to events such as rain on snow, which do not occur in all winters and regions, and in irregular intervals [43]. Furthermore the amount of data used in the calculation varies from site to site. While this influence was reduced for the Sentinel-1 product by utilizing the percentile, an effect due to data coverage cannot be excluded for the Envisat ASAR GM maps. However, the Envisat ASAR GM coverage of the Usa Basin site is similar to that of the Northern Alaska region and therefore may not explain the discrepancies. Deviations specifically found for the Alaskan North Slope occurred across different vegetation types and also included the lowland areas.

Some undesired effects during the radiometric calibration of Sentinel-1 data with the SNAP toolbox are apparent. Different results were obtained when only a subset of the scene was processed. We therefore always used the whole scene in the calibration process, however influences due to calibration cannot be estimated. There may also be differences regarding the calibration for ASAR GM datasets, which covered often much larger areas than Sentinel-1 scenes, extending far into the Arctic Ocean. The abundance of small lakes in many Arctic regions may influence the results. While a multitude of small water bodies (with floating ice and therefore high backscatter in December) may be too small to be detected as in the coarser Envisat ASAR GM maps, they can be distinguished for Sentinel-1. 
The percentile images of calibration and evaluation sites were compared to the CAVM, which is currently the only available consistent circumpolar land cover map with sufficient thematic content [15]. The CAVM team [39] identified three different moisture levels for certain vegetation physiognomic units of the CAVM. It can therefore be used for the SAR-based classification approach [13]. In fact, all tested sites indicated lower median values for wetter areas (see Figure 8). However, comparisons between sites indicated issues determining a global threshold between classes. Values of similar classes were lower in the Lena Delta than for the Usa Basin or Northern Alaska. Even the median value of the dry class 'Prostrate dwarf-shrub, herb tundra' in the Lena Delta were lower than some wet or moist classes of the Northern Alaska site. This may result from landscape heterogeneity which is pronounced in the Lena Delta [23,44]. Furthermore the differences in sample size must be considered, which varies from site to site (see Table 3). The CAVM is based on satellite data with a spatial resolution of only about $1 \mathrm{~km}$. Specifically the moist classes consist of wetter and drier patches. Averaging represents the dominating effect only. Dry CAVM classes are underrepresented in the selected areas $(0.5 \%$ of samples) and results therefore do not allow for conclusions on the suitability of the threshold method to derive wetness levels from the Sentinel-1 data. Furthermore, the introduced normalization method may not be applicable for lake ice, as the slope is derived depending on backscatter amount. For lake ice, backscatter strongly depends on whether the lake is frozen to the bottom or if the ice is floating, leading to essential backscatter differences, while the slope remains largely unchanged.

The normalization approach may be also suitable to aid soil moisture retrieval. The slope does not change with variations in soil moisture as long as roughness and volume scattering are constant (e.g., [5]). Slope values derived from winter data may therefore be applicable to normalize data independent of acquisition time. Variations of backscatter due to phenology is expected to be limited in tundra regions at C-band but may need to be considered.

Table 3. Sample size as depicted in Figure 8 (divided by 1000), distinguished by region (Figure 1). CAVM classes are classified as wet (blue), moist (green), dry (yellow) and rock (grey; moisture classes according to [39]).

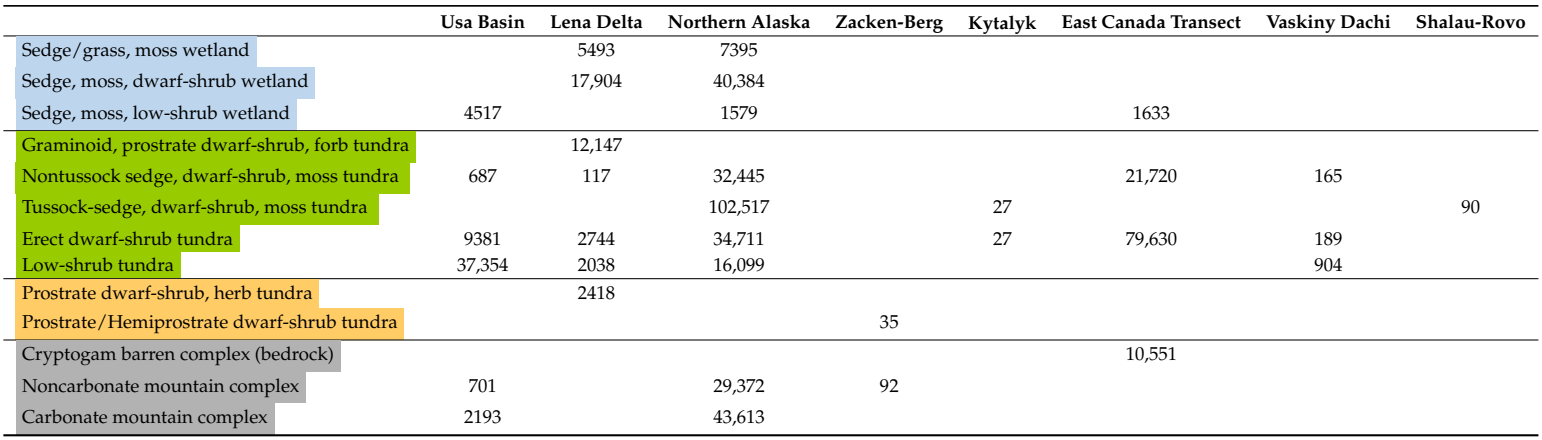

\section{Conclusions}

Normalization of SAR data to a common incidence angle is required for many applications, but this is challenging in heterogeneous landscapes with varying angular dependencies. The analyses of angular signatures of winter C-band backscatter of Arctic land cover types revealed a linear relationship between the incidence angle dependencies of $\sigma^{0}$ and $\sigma^{0}$ itself, which can be exploited for normalization. Images normalized using this new approach showed good agreements with results processed on a common pixel by pixel based approach which requires processing of many scenes acquired from different orbits. However, deviations were found in mountainous regions, where the assumed linear relationship was no longer valid due to an increase in incidence angle range. Although the simplified normalization approach is valid for tundra and the transition zone to boreal forest, the use of multiple acquisitions (and statistics such as use of percentiles) may be beneficial for applications in order to account for other effects (such as rain on snow and speckle). 
By comparing the results of Sentinel-1, normalized by the new slope function, and Envisat ASAR GM results, normalized on a pixel by pixel basis, some site specific offsets became apparent, which could not be explained explicitly with the available reference data. They may result from scale and thematic content differences. Nevertheless, the benefit of using higher resolution SAR data can be expected in these heterogeneous landscapes, making less computationally intensive normalization approaches, like the one presented in this paper, essential.

Acknowledgments: This study has been funded by the European Space Agency project DUE GlobPermafrost (Contract Number 4000116196/15/I-NB), which is lead by the Zentralanstalt für Meteorologie und Geodynamik. This work was furthermore supported by the Austrian Science Fund under Grant [I 1401] (Joint Russian-Austrian project COLD-Yamal). TanDEM-X data was made available by DLR through PI agreement HYDR1262.

Author Contributions: B.W. developed the concept of the study, conducted all data processing and analysis, the literature research, designed the figures and wrote the majority of the manuscript. A.B. contributed to the concept development of the study, the development of the methodology, the interpretation of the results and writing of the manuscript. R.G. has contributed to the revision of the manuscript.

Conflicts of Interest: The authors declare no conflict of interest. The founding sponsors as listed within the acknowledgments section had no role in the design of the study; in the collection, analyses, or interpretation of data; in the writing of the manuscript, and in the decision to publish the results.

\section{References}

1. Ulaby, F.T.; Moore, R.K.; Fung, A. Microwave Remote Sensing-Active and Passive; Artech House: Norwood, MA, USA, 1982; Volume II.

2. Mladenova, I.E.; Jackson, T.J.; Bindlish, R.; Hensley, S. Incidence Angle Normalization of Radar Backscatter Data. IEEE Trans. Geosci. Remote Sens. 2013, 51, 1791-1804.

3. Wickel, A.J.; Jackson, T.J.; Wood, E.F. Multitemporal monitoring of soil moisture with RADARSAT SAR during the 1997 Southern Great Plains hydrology experiment. Int. J. Remote Sens. 2001, 22, 1571-1583.

4. Loew, A.; Ludwig, R.; Mauser, W. Derivation of Surface Soil Moisture From ENVISAT ASAR Wide Swath and Image Mode Data in Agricultural Areas. IEEE Trans. Geosci. Remote Sens. 2006, 44, 889-899.

5. Pathe, C.; Wagner, W.; Sabel, D.; Doubkova, M.; Basara, J.B. Using ENVISAT ASAR Global Mode Data for Surface Soil Moisture Retrieval Over Oklahoma, USA. IEEE Trans. Geosci. Remote Sens. 2009, 47, 468-480.

6. Baup, F.; Mougin, E.; Hiernaux, P.; Lopes, A.; Rosnay, P.D.; Chenerie, I. Radar Signatures of Sahelian Surfaces in Mali Using ENVISAT-ASAR Data. IEEE Trans. Geosci. Remote Sens. 2007, 45, 2354-2363.

7. Van Doninck, J.; Wagner, W.; Melzer, T.; Baets, B.D.; Verhoest, N.E.C. Seasonality in the Angular Dependence of ASAR Wide Swath Backscatter. IEEE Geosci. Remote Sens. Soc. 2014, 11, 1423-1427.

8. Bartsch, A.; Pointner, G.; Leibman, M.O.; Dvornikov, Y.A.; Khomutov, A.V.; Trofaier, A.M. Circumpolar Mapping of Ground-Fast Lake Ice. Front. Earth Sci. 2017, 5, doi:10.3389/feart.2017.00012.

9. Mäkynen, M.P.; Manninen, A.T.; Similä, M.H.; Karvonen, J.A.; Hallikainen, M.T. Incidence Angle Dependence of the Statistical Properties of C-Band HH-Polarization Backscattering Signatures of the Baltic Sea Ice. IEEE Geosci. Remote Sens. Soc. 2002, 40, 2593-2605.

10. Frison, P.L.; Mougin, E. Use of ERS-1 wind scatterometer data over land surfaces. IEEE Geosci. Remote Sens. Soc. 1996, 34, 550-560.

11. Menges, C.H.; Van Zyl, J.J.; Hill, G.J.E.; Ahmad, W. A procedure for the correction of the eVect of variation in incidence angle on AIRSAR data. Int. J. Remote Sens. 2001, 22, 829-841.

12. Bartsch, A.; Trofaier, A.; Hayman, G.; Sabel, D.; Schlaffer, S.; Clark, D.; Blyth, E. Detection of Open Water Dynamics with ENVISAT ASAR in Support of Land Surface Modelling at High Latitudes. Biogeosciences 2012, 9, 703-714.

13. Widhalm, B.; Bartsch, A.; Heim, B. A novel approach for the characterization of tundra wetland regions with C-band SAR satellite data. Int. J. Remote Sens. 2015, 36, 5537-5556.

14. Bartsch, A.; Widhalm, B.; Kuhry, P.; Hugelius, G.; Palmtag, J.; Siewert, M.B. Can C-band synthetic aperture radar be used to estimate soil organic carbon storage in tundra? Biogeosciences 2016, 13, 5453-5470.

15. Bartsch, A.; Höfler, A.; Kroisleitner, C.; Trofaier, A.M. Land Cover Mapping in Northern High Latitude Permafrost Regions with Satellite Data: Achievements and Remaining Challenges. Remote Sens. 2016, 8, 979. 
16. Attema, E.; Bargellini, P.; Edwards, P.; Levrini, G.; Lokas, S.; Moeller, L.; Rosich-Tell, B.; Secchi, P.; Torres, R.; Davidson, M.; et al. Sentinel-1: The Radar Mission for GMES Operational Land and Sea Services. ESA Bull. 2007, 131, 10-17.

17. Potin, P. Sentinel-1 User Handbook; European Space Agency (ESA): Paris, France, 2013.

18. Torres, R.; Snoeij, P.; Geudtner, D.; Bibby, D.; Davidson, M.; Attema, E.; Potin, P.; Rommen, B.; Floury, N.; Brown, M.; et al. GMES Sentinel-1 mission. Remote Sens. Environ. 2012, 120, 9-24.

19. Lehner, B.; Döll, P. Development and Validation of a Global Database of Lakes, Reservoirs and Wetlands. J. Hydrol. 2004, 296, 1-22.

20. Bicheron, P.; Defourny, P.; Brockmann, C.; Schouten, L.; Vancutsem, C.; Huc, M.; Bontemps, S. GlobCover: Products Description and Validation Report; Technical Report; MEDIASFrance: Toulouse, France, 2008.

21. Walker, D.; Gould, W.; Maier, H.; Raynolds, M. The Circumpolar Arctic Vegetation Map: AVHRR-derived base maps, environmental controls, and integrated mapping procedures. Int. J. Remote Sens. 2002, 23, 4551-4570.

22. Santoro, M.; Strozzi, T. Circumpolar digital elevation models $>55^{\circ} \mathrm{N}$ with links to geotiff images. PANGAEA 2012, doi:10.1594/PANGAEA.779748.

23. Schneider, J.; Grosse, G.; Wagner, D. Land cover classification of tundra environments in the Arctic Lena Delta based on Landsat 7 ETM+ data and its application for upscaling of methane emissions. Remote Sens. Environ. 2009, 113, 380-391.

24. Virtanen, T.; Mikkola, K.; Nikula, A. Satellite image based vegetation classification of a large area using limited ground reference data: A case study in the Usa Basin, north-east European Russia. Polar Res. 2004, 23, $51-66$.

25. Jorgenson, M.T.; Heiner, M. Ecosystems of Northern Alaska; Unpublished 1:2.5 Million-Scale Map; ABR, Inc.: Fairbanks, AK, USA, 2003.

26. Bartsch, A.; Grosse, G.; Kääb, A.; Westermann, S.; Strozzi, T.; Wiesmann, A.; Duguay, C.; Seifert, F.M.; $\mathrm{Obu}, \mathrm{J}$; Goler, R. GlobPermafrost How space-based earth observation supports understanding of permafrost. In Proceedings of the ESA Living Planet Symposium 2016, Prague, Czech Republic, 9-13 May 2016; p. 6.

27. Palmtag, J.; Hugelius, G.; Lashchinskiy, N.; Tamstorf, M.P.; Richter, A.; Elberling, B.; Kuhry, P. Storage, Landscape Distribution, and Burial History of Soil Organic Matter in Contrasting Areas of Continuous Permafrost. Arct. Antarct. Alp. Res. 2015, 47,71-88.

28. Siewert, M.B.; Hanisch, J.; Weiss, N.; Kuhry, P.; Maximov, T.C.; Hugelius, G. Comparing carbon storage of Siberian tundra and taiga permafrost ecosystems at very high spatial resolution. J. Geophys. Res. Biogeosci. 2015, 120, 1973-1994.

29. Leibman, M.; Khomutov, A.; Gubarkov, A.; Mullanurov, D.; Dvornikov, Y. The research station Vaskiny Dachi, Central Yamal, West Siberia, Russia A review of 25 years of permafrost studies. Fennia 2015, 193, 3-30.

30. Khomutov, A.; Leibman, M. Landslides in Cold Regions in the Context of Climate Change; Chapter Assessment of Landslide Hazards in a Typical Tundra of Central Yamal, Russia; Springer International Publishing: Cham, Switzerland, 2014; pp. 271-290.

31. Quebec Ministry of Natural Resources. Vegetation Zones and Bioclimatic Domains of the Quebec Province; Quebec Ministry of Natural Resources: Quebec, QC, Canada, 2003.

32. Lemieux, J.M.; Fortier, R.; Talbot-Poulin, M.C.; Molson, J.; Therrien, R.; Ouellet, M.; Banville, D.; Coch, M.; Murray, R. Groundwater occurrence in cold environments: Examples from Nunavik, Canada. Hydrol. J. 2016, 24, 1497-1513.

33. Hachem, S.; Allard, M.; Duguay, C. Using the MODIS land surface temperature product for mapping permafrost: An application to northern Québec and Labrador, Canada. Permafr. Periglac. Process. 2009, 20, doi:10.1002/ppp.672.

34. Mougin, E.; Lopes, A.; Frison, P.L.; Proisy, C. Preliminary analysis of ERS-1 wind scatterometer data over land surfaces. Int. J. Remote Sens. 1995, 16, 391-398.

35. Woodhouse, I. Introduction to Microwave Remote Sensing; Taylor \& Francis: New York, NY, USA, 2006.

36. Bergstedt, H.; Zwieback, S.; Bartsch, A.; Leibman, M. Dependence of C-Band Backscatter on Ground Temperature, Air Temperature and Snow Depth in Arctic Permafrost Regions. Remote Sens. 2018, 10, 142.

37. Naeimi, V.; Paulik, C.; Bartsch, A.; Wagner, W.; Kidd, R.; Boike, J.; Elger, K. ASCAT Surface State Flag (SSF): Extracting Information on Surface Freeze/Thaw Conditions from Backscatter Data Using an Empirical Threshold-Analysis Algorithm. IEEE Trans. Geosci. Remote Sens. 2012, 50, 2566-2582. 
38. Bergstedt, H.; Bartsch, A. Surface State across Scales; Temporal and Spatial Patterns in Land Surface Freeze/Thaw Dynamics. Geosciences 2017, 7, 65.

39. CAVM Team. Circumpolar Arctic Vegetation Map; (1:7,500,000 Scale), Conservation of Arctic Flora and Fauna (CAFF) Map No. 1; U.S. Fish and Wildlife Service: Anchorage, AK, USA, 2003.

40. Gauthier, Y.; Bernier, M.; Fortin, J.P. Aspect and incidence angle sensitivity in ERS-1 SAR data. Int. J. Remote Sens. 1998, 19, 2001-2006.

41. Forbes, B.C.; Kumpula, T.; Meschtyb, N.; Laptander, R.; Macias-Fauria, M.; Zetterberg, P.; Verdonen, M.; Skarin, A.; Kim, K.Y.; Boisvert, L.N.; et al. Sea ice, rain-on-snow and tundra reindeer nomadism in Arctic Russia. Biol. Lett. 2016, 12, doi:10.1098/rsbl.2016.0466.

42. Kumpula, T.; Forbes, B.C.; Stammler, F.; Meschtyb, N. Dynamics of a Coupled System: Multi-Resolution Remote Sensing in Assessing Social-Ecological Responses during 25 Years of Gas Field Development in Arctic Russia. Remote Sens. 2012, 4, 1046-1068.

43. Bartsch, A. Ten Years of SeaWinds on QuikSCAT for Snow Applications. Remote Sens. 2010, 2, 1142-1156.

44. Muster, S.; Langer, M.; Heim, B.; Westermann, S.; Boike, J. Subpixel heterogeneity of ice-wedge polygonal tundra: A multi-scale analysis of land cover and evapotranspiration in the Lena River Delta, Siberia. Tellus $B$ Chem. Phys. Meteorol. 2012, 64, doi:10.3402/tellusb.v64i0.17301.

(C) 2018 by the authors. Licensee MDPI, Basel, Switzerland. This article is an open access article distributed under the terms and conditions of the Creative Commons Attribution (CC BY) license (http://creativecommons.org/licenses/by/4.0/). 